\title{
Current Status of the Front Ends at the SLS
}

\author{
Q.Chen, H.Bächli, C.Höchli, R.Wullschleger, R.Abela, G.Ingold, L.Schulz, \\ C.Schulze-Briese, M.Stampanoni, X.Wang,
}

Paul Scherrer Institut, Swiss Light Source, CH-5232 Villigen-PSI, Switzerland

\begin{abstract}
At the Swiss Light Source, the super-bend bending magnet front end, combining multi-function components and optics for the TOMCAT beamline, is in operation. The Femto front end, with a special design, has been installed recently. A new type of CVD filter for the PX Front End and NEG coating technology applied on the components both show good results. All will be described in this article.
\end{abstract}

Keywords: Super-bend, Front End, Femto, CVD, NEG

PACS: 07.85. Qe; 07.85. Fv; 02.70.Bf

\section{INDRODUCTION}

At the Swiss Light Source, seven Insertion Device Front Ends (IDFEs) and five Bending Magnet Front Ends (BMFEs) are in operation, and new FEs are under construction and will be installed by the end of 2006. The FEs operate with remarkable performance and high reliability. The optimization and the standardization of the FE layout, component design and system definition, together with results, have been presented in [1]. Here, the new design for the super-bend BMFE and Femto FE, and some results for a new CVD filter and NEG coating technology will be presented.

\section{SUPER-BEND BMFE}

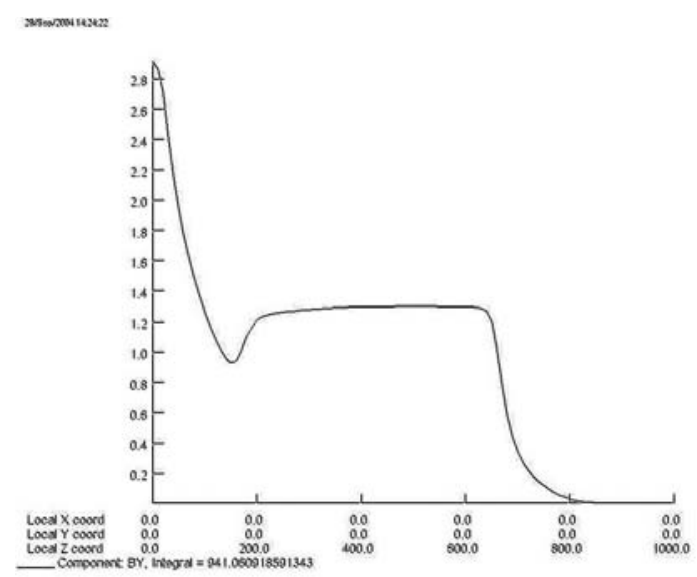

FIGURE 1. SLS Super-bend field

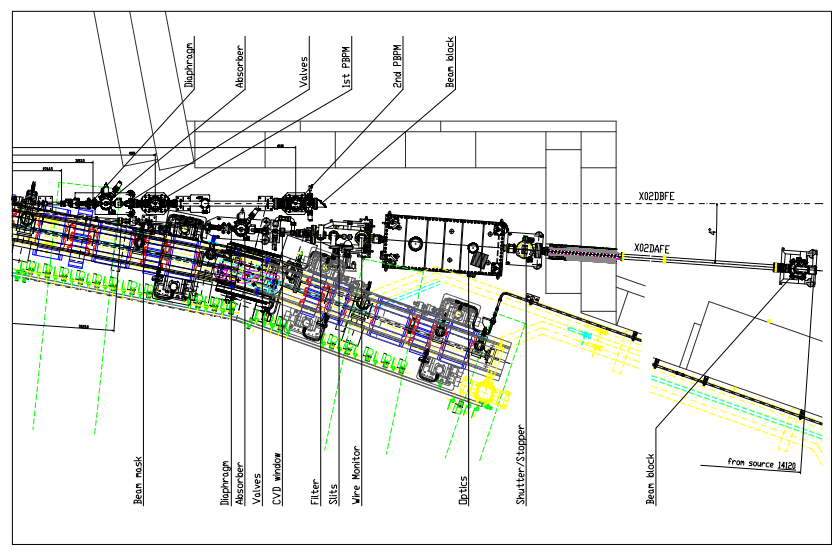

FIGURE 2. X02DFE General Layout

There are three super-bends at the SLS, which are in section 2 for the TOMCAT beamline, in section 6 for the PXIII beamline and in section 10 for the Super XAS beamline. Each super-bend section BMFE has DA and DB branches. The DA branch has the super-bend field of 2.9 Tesla, and the DB branch has the normal field of 1.4 Tesla. The super-bend field distribution along the axis is shown in figure 1. The super-bend BMFE DA contains not only 
the standard components, such as diaphragm, absorber, shutter/stopper and valves, but also a CVD window, filter, slits, wire beam monitor, beam block and optics [2]. The general layout of X02DFE for the TOMCAT beamline is shown in figure 2 .

The ultra-high vacuum (UHV) section is short and the optics are located in the ring tunnel. The closer the optics are to the source, the smaller the size of optical components that can be used. Therefore, the cost of the beamline can be reduced significantly. It is very important that the optics must be carefully calibrated and tested, since access to the ring tunnel is limited during machine operation.

\section{FEMTO FE}

The Femto insertion needs a Front End to absorb the power emitted by the W138 Modulator Wiggler. The Femto FE [3] consists of a set of UHV components, such as diaphragms, photon shutter, and valves with associated control cables and fluid supply. At the end of the Femto FE, there are two mirrors to transport the laser and the visible synchrotron light from W138 to a diagnostic station. A compact component design allows the Femto FE to fit into the very limited space between the magnets on the girder of the Femto Quadrupole Triplet, shown in Figure 3. Table 1 shows how the total emitted power of $14 \mathrm{~kW}$ is distributed on the three components.

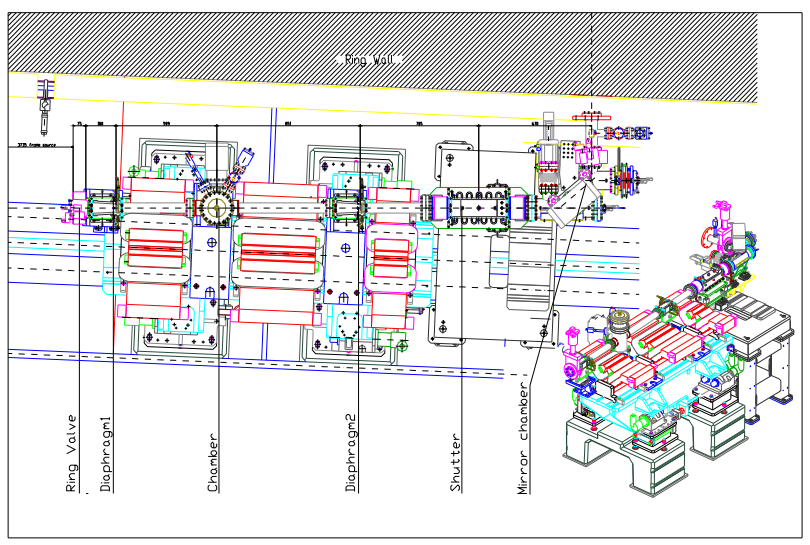

FIGURE 3. Femto Front End General Layout

TABLE 1. The location and the absorbed power on the main components of the Femto FE.

\begin{tabular}{|c|c|c|c|c|c|c|}
\hline Name & $\begin{array}{l}\text { Distance } \\
(\mathbf{m})\end{array}$ & $\begin{array}{c}\text { Total power } \\
(\mathbf{k W})\end{array}$ & $\begin{array}{c}\text { Absorbed } \\
\text { power }(k W)\end{array}$ & $\begin{array}{c}\text { Max. power } \\
\text { density }\left(W / \mathbf{m m}^{2}\right)\end{array}$ & $\begin{array}{c}\text { Tilt angle } \\
\text { (degree) }\end{array}$ & $\begin{array}{c}\text { Tilt power } \\
\text { density }\left(\mathbf{W} / \mathbf{m m}^{2}\right)\end{array}$ \\
\hline Diaphragm 1 & 3.81 & 14 & 2.4 & 230 & 2.5 & 10 \\
\hline Diaphragm 2 & 5.26 & 11.6 & 2.6 & 150 & 2.5 & 6.5 \\
\hline Shutter & 6.15 & 9 & 9 & 140 & 1.5 & 3.7 \\
\hline
\end{tabular}
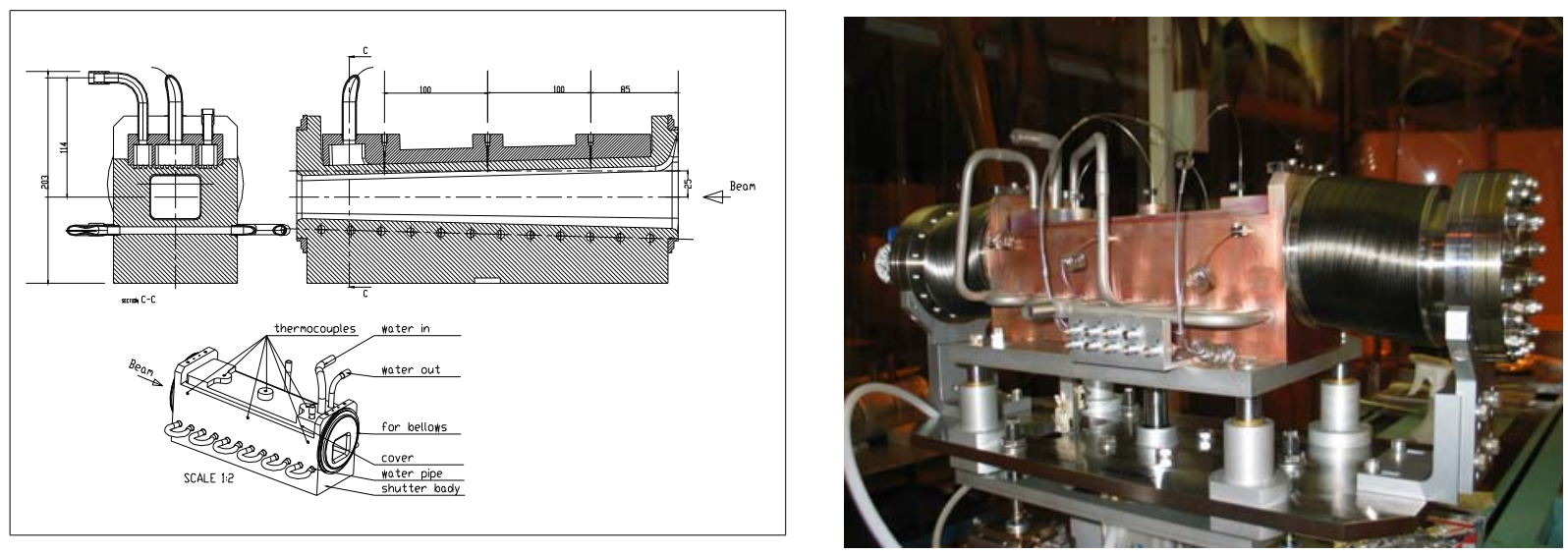

FIGURE 4. The shutter body structure (left) and the entire shutter including the pneumatic manipulator and two bellows (right). 
A highly efficient water-cooling system on the shutter, which is the same as used for the photon shutter of SLS IDFE [4], is used. A pneumatic manipulator moves the shutter body in between two positions: in the upper position, the shutter is open and the beam passes through; in the lower position, the shutter is closed and the main part of beam is blocked, see figure 4 .

The steady-state thermal analysis of the shutter was performed with the finite element code ANSYS 10.0. The 3D thermal elements (type solid 70) are used for modelling the shutter head structure. The predicted power density distribution is shown in Figure 5. A total power of $14 \mathrm{~kW}$ is applied. The heat transfer coefficient for the cooling water is assumed to be $0.0113 \mathrm{~W} / \mathrm{mm}^{2}$. The detailed information about the parameters and analysis is presented in [5]. There are 9 thermocouples on the shutter body to measure the temperature. The recorded temperatures during the Femto FE commissioning are lower than those predicted in figure 6.

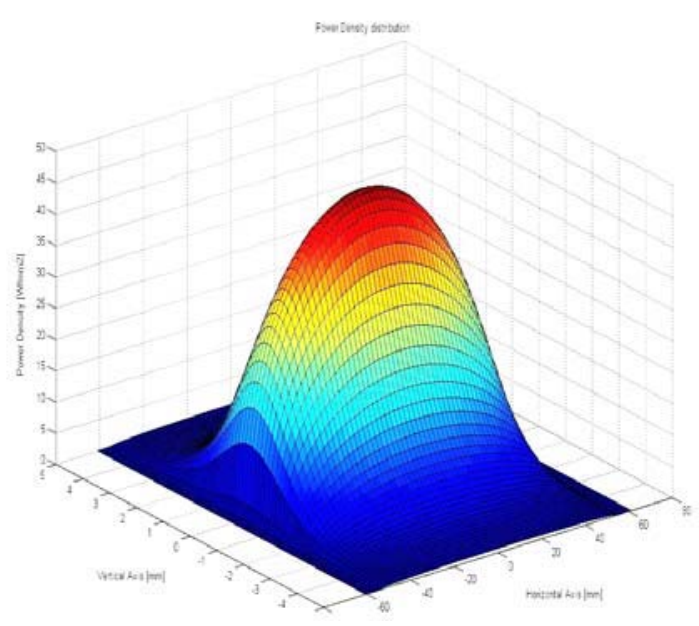

FIGURE 5. The power distribution@10 m

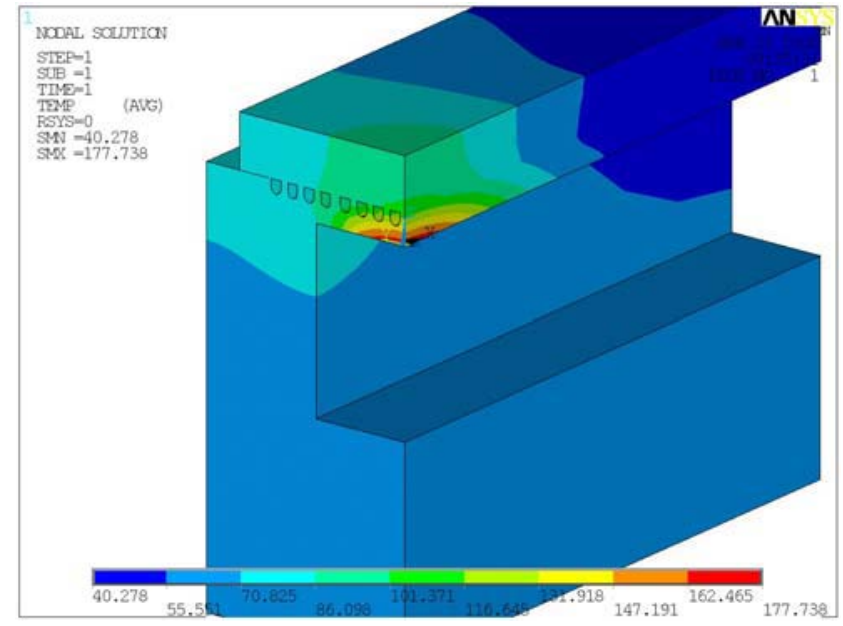

FIGURE 6. The temperature distribution on the shutter body

\section{NEG PUMP COATING}

The inner surface of the shutter body for the Femto FE has been coated with a NEG TiVZr film; therefore the shutter also acts as a NEG pump [6]. The measured vacuum during the commissioning phase shows that this NEG coating has significantly improved the vacuum in the Femto FE.

The NEG pump is a kind of CapaciTorr pump, which absorbs active gases with Non-Evaporable Getter material. It has a high pumping speed for all active gases, a high capacity and can work down to $10^{-12}$ mbar. It is not only oil free and vibration free, but it can also work at room temperature without power after activation. The pumping process consists of sorption, by chemical reaction, of active gas molecules impinging on the clean metal surface of each particle of getter material contained in the pump cartridge. A clean metal surface means one not covered by oxides or carbide layers which result when the getter material is exposed to air during manufacturing, installation or air venting steps. To obtain this clean metal surface, the getter material does not need to be evaporated as required for titanium in a titanium sublimation pump. It only needs to be heated, under dynamic vacuum, to diffuse the passivation layer, covering the surface of each getter particle, into the bulk of the getter material.

\section{CVD FILTER}

A new version of CVD (Chemical Vapour Deposition) diamond filters [7] was designed and implemented at the SLS protein crystallography (PX) beamlines for thermal and spectral management of the beam emitted by small gap in-vacuum undulators U19. The low critical energy of U19 at SLS medium energy storage ring results in a high power deposition in front-end filters and Be-windows, which would eventually destroy the latter if no upstream filtering was in place. The high thermal conductivity, low expansion coefficient, radiation hardness, UHV compatibility and excellent surface roughness of better than $5 \mathrm{~nm}$ (rms) make CVD-diamond ideally suited as a filter material. 
The filter head consists of two water cooled holders and a CVD-diamond disk of $200 \mu \mathrm{m}$ thickness with a diameter of $50 \mathrm{~mm}$. The new design aims at a further reduction of the stress in the diamond wafer by lowering the maximal temperature without inducing additional stress by the cooling mechanism. This is reached by coupling the CVD-diamond disk by means of liquid InGaSn-eutectic to the water-cooled $\mathrm{Cu}$ holder (see figure 7.). The CVD filter is located at $12.38 \mathrm{~m}$ from the centre of the insertion device. The two holders are fixed together with the top CF250 flange and placed in the chamber. In the centre there are apertures of $7 \mathrm{~mm}$ and $11 \mathrm{~mm}$ in the vertical and horizontal directions, respectively. The plate on the downstream holder is Ni coated $(20 \mu \mathrm{m})$. This surface is covered by a thin layer of GALINSTAN, and the CVD-diamond disk is placed on this layer. Although the CVD-diamond disk is kept in position by the high surface tension of the eutectic, four pins on the upstream holder apply a small force to the disk to prevent a degradation of the thermal contact. Two thermocouples are inserted into the small holes on the pin to measure the temperatures of the CVD-diamond disk.

The filters with the new design have been installed in the FEs of X06SA, X05LA and X10SA since 2004. Closing the undulator gap from $38 \mathrm{~mm}$ to $5.5 \mathrm{~mm}$ at $350 \mathrm{~mA}$ ring current only leads to an increase of the thermocouple reading of $5{ }^{\circ} \mathrm{C}$. The moderate temperatures, shown in figure 8 , will increase the lifetime of the CVD disk. Despite the presence of the eutectic, the pressure in the front-end sector does not exceed $10^{-9} \mathrm{mbar}$.

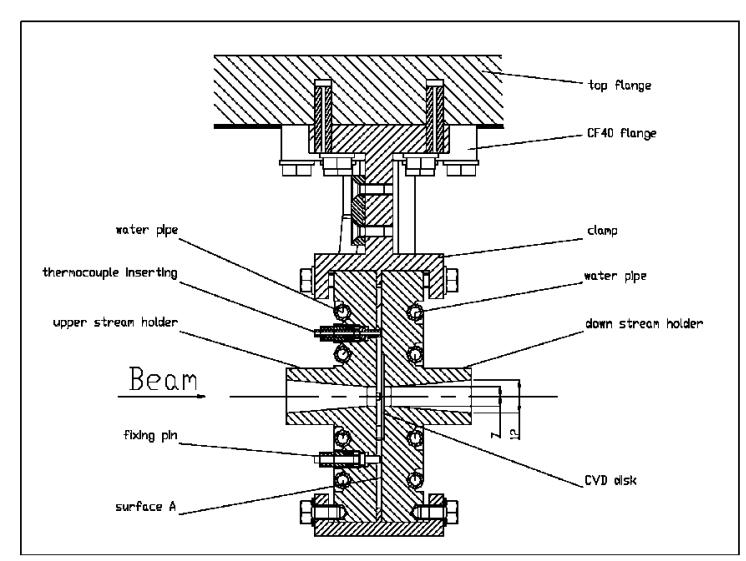

FIGURE 7. The indirectly water-cooled CVD-filter holder

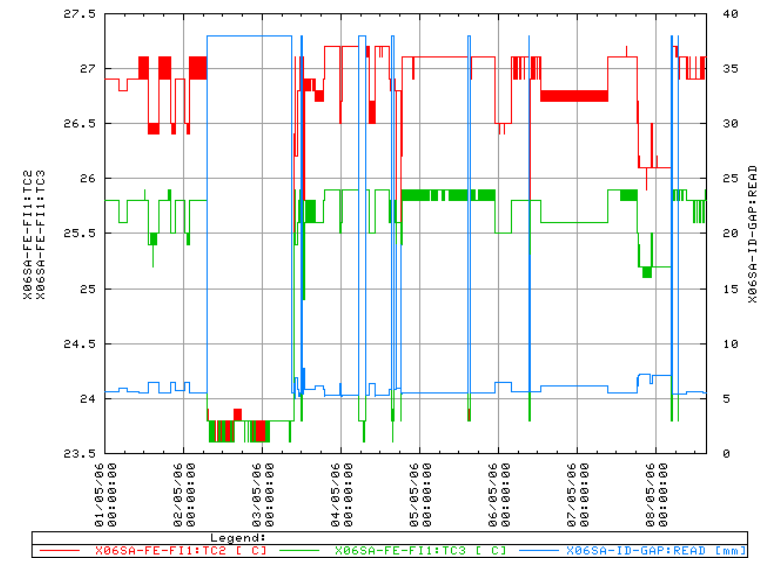

FIGURE 8. The temperature readings on the filter head of X06SA Front End, for a ring current $\mathrm{I}=300 \mathrm{~mA}$, the minimum Undulator gap $5.5 \mathrm{~mm}$.

\section{ACKNOWLEDGMENTS}

The authors would like to thank all the service groups at PSI for their excellent work and support.

\section{REFERENCES}

1. Q.Chen, R. Abela, H.Auderset, B.Frauenfelder, M.Janousch, H.Kalt, B.Patterson, M.Shi, D.Vermeulen, SLS Front Ends for Insertion Device Beamline, PSI Annual Report 1999, SLS Annex.

2. Q.Chen, M.Stampanoni, H.Kalt, Specifications for X02DAFE and the $1^{\text {st }}$ section of X02DBFE at SLS, SLS-SPC-TA-2004-246 Oct. 2004.

3. G.Ingold, R.Abela, P.Beaud, Q.Chen, D.Groulimond, S.Johnson, L.Rivkin, M.Rohrer, V.Schlott, T.Schmidt, L.Schulz, A.Streun, F.van der Veen, F.Wei and A.Tarnovsky, Status of the Femto Project, PSI Annual Report 2004, SLS Annex.

4. Q.Chen, R.Abela, H.Auderset, B.Frauenfelder, M.Janousch, H.Kalt, M.Lange, B.D.Patterson and M.Shi, A Photon Shutter for insertion device front ends at the SLS, Nuclear Instruments and Methods in Physics Research A 467-468 (2001) $752-757$.

5. X.Wang, Thermal Analysis of a photon shutter at the SLS by finite element method, SLS AMI report ITN-060421.

6. The SAES Getter Group, CapaciTorr ${ }^{\circledR}$ Non-Evaporable Getter Pump.

7. Q.Chen, M.Kropf, M.Lange, B.Patterson, R.Schneider, M.Shi, R.Wullschleger and C.Schulze-Briese, Design and Performance of white beam CVD-Filters for SLS in-vacuum undulators, PSI Annual Report 2004, SLS Annex 